\title{
ENVIRONMENTAL FORENSIC INVESTIGATION OF MYSTERY SEDIMENT PLUMES AT BARTON SPRINGS, TEXAS
}

Lindsey Sydow, P.G.

City of Austin Watershed Protection, 505 Barton Springs Rd., Austin, TX, 78704, United States, lindsey.sydow@austintexas.gov

David A. Johns, P.G.

City of Austin Watershed Protection, 505 Barton Springs Rd., Austin, TX, 78704, United States, david.johns@austintexas.gov

Sarah J. Zappitello, P.G.

City of Austin Watershed Protection, 505 Barton Springs Rd., Austin, TX, 78704, United States, sjzappitello@gmail.com

Thain Maurer, C.H.M.M.

City of Austin Watershed Protection, 505 Barton Springs Rd., Austin, TX, 78704, United States, thain.maurer@austintexas.gov

\begin{abstract}
The City of Austin Watershed Protection Department (WPD) in Austin, Texas maintains a spill response plan to protect Barton Springs, one of the largest springs in the state that also functions as a municipal swimming pool, endangered species habitat, and well-studied karst research site. From December 18-20, 2018, three discrete sediment plumes of unknown origin emerged from Main Barton Spring and Eliza Spring, presenting an atypical spill scenario. Unlike the majority of spills, where staff respond to a known location, pollutant, and spill volume, WPD responders and staff at the Barton Springs Edwards Aquifer Conservation District (BSEACD) had to work backward from evidence at the springs to identify the plumes' source.
\end{abstract}

Of the four springs that make up the Barton Springs Complex, the highest turbidity was observed at Main Barton and Eliza Springs, which narrowed the source to the Manchaca groundwater basin based on previous regional groundwater traces. The concentrated spikes in turbidity associated with each plume indicated minimal dispersion and thus a source relatively near the springs. The white color of the plume on the 19th was typical of either construction runoff or bentonite grout used in well installation. No significant rainfall had occurred in the days prior to the event, and the plumes were not typical of storm responses. Following these lines of evidence, the source was identified as nearby drilling of a residential geothermal heat pump well system located approximately 1,250 meters from Main Barton Spring. The tim- ing of the plumes correlated to voids encountered and well grouting as noted by the driller during initial discussions on site, yielding approximately a 315-415 meter/hour (1,030-1,360 feet/hour) groundwater velocity: within the range of velocities documented by groundwater tracing. Following this incident, WPD and BSEACD officials updated drilling protocols and communication procedures regarding future drilling projects in the area to improve WPD's ability to respond quickly to similar events in the future.

Because the sediment plumes only increased turbidity for short periods (no other parameters were affected) and posed no other significant threat to the health and safety of humans or the resident endangered salamanders, the incident presented unique opportunities to (1) test our Barton Springs Spill Response Plan readiness, (2) gather data similar to a groundwater tracing study, and (3) improve the Barton Springs Spill Response Plan and update drilling and notification protocols between overlapping regulatory agencies.

\section{Introduction}

At approximately 12:45 on December 19, 2018, one of the lifeguards at Barton Springs sent a photo of the rapidly-turning-white pool to WPD's lead salamander biologist. Several representatives from the department made their way to the pool to investigate the cloudy white plume (Figure 1) and check on the welfare of the salamanders. A quick check of 15-minute field parameters that are collected continuously at Main Barton Spring 


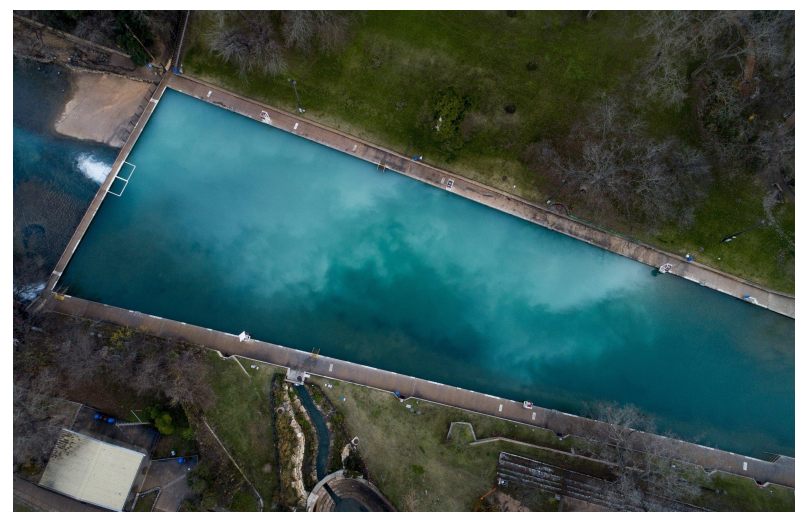

Figure 1. Drone footage of the white sediment plume (Plume 2) in Barton Springs Pool on December 19, 2018 (Bradshaw, 2018).

revealed that all parameters were within typical ranges except for turbidity, which had quickly risen to significantly higher concentrations than had been observed as a result of natural events.

The lifeguards informed WPD personnel on site that there had been a reddish-brown high turbidity discharge the previous evening as well. The recorded field parameters showed that turbidity had risen roughly three times as high during that event (Plume 1) as during the white plume that was quickly circulating throughout the pool (Plume 2). The cloudy water stopped discharging from the springs as quickly as it had begun. While WPD was still searching for the source of Plumes 1 and 2 on December 20,2018, a third plume emerged from the spring at approximately the same time of day as Plume $2 \mathrm{had}$ on the 19th. Plume 3 was brown. These events garnered much local concern for the city's most popular swimming hole which is remarkably clear under normal circumstances (Figure 2).

This paper describes the forensic approach taken by the City of Austin and regulatory partners in determining the source of these discharges and explores how communication has been strengthened and response protocols updated as a result of this event.

\section{Hydrogeologic Setting \& Background}

The Edwards Aquifer is a major karst aquifer that extends across central and southwest Texas along the Balcones Fault Zone. The aggressively weathered, lateCretaceous Edwards Formation outcrops along the fault zone, generally dipping to the southeast where it is confined by the overlying Del Rio Formation. It is divided regionally by groundwater divides into 3 segments, the

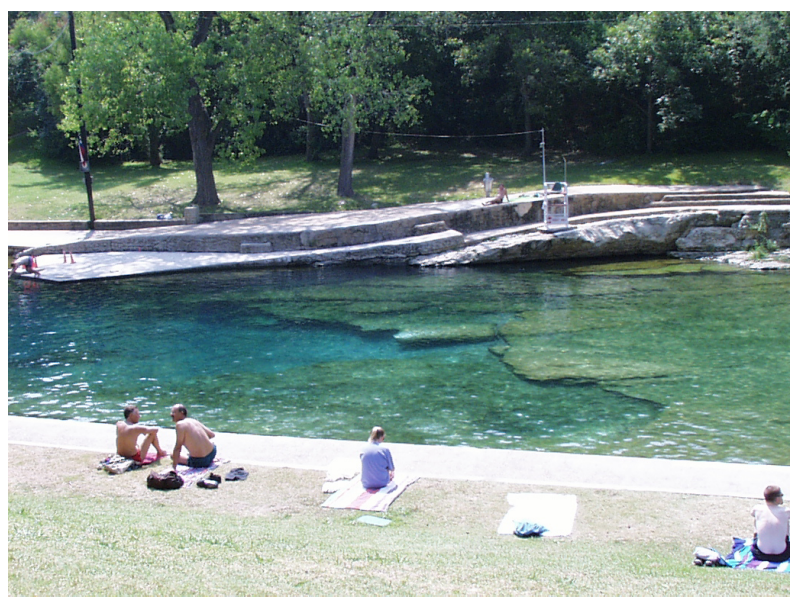

Figure 2. Barton Springs Pool is clear under typical conditions.

middle of which comprises much of south Austin and is referred to as the Barton Springs segment of the Edwards Aquifer (BSEA) (Figure 3). The aquifer becomes saline deeper and east of the confined zone, where flow paths are more stagnant and residence times are longer.

The major discharge point for the BSEA is Barton Springs, the largest spring in Austin and the 4th largest in Texas (Brune, 2002). The BSEA primarily recharges from the streams that flow across the Edwards Group (Figure 4) south of the Colorado River in Austin: Barton, Williamson, Slaughter, Bear, Little Bear, and Onion Creeks, with the Blanco River also contributing under lower aquifer conditions (Smith et al., 2012; Johnson et

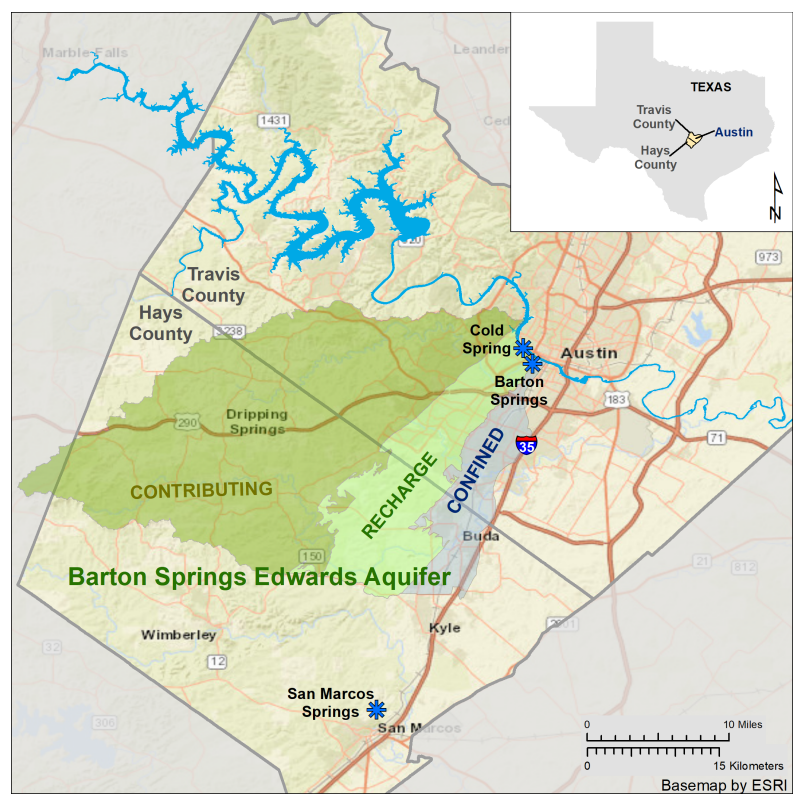

Figure 3. Barton Springs Edwards Aquifer in and near Austin, Texas. 


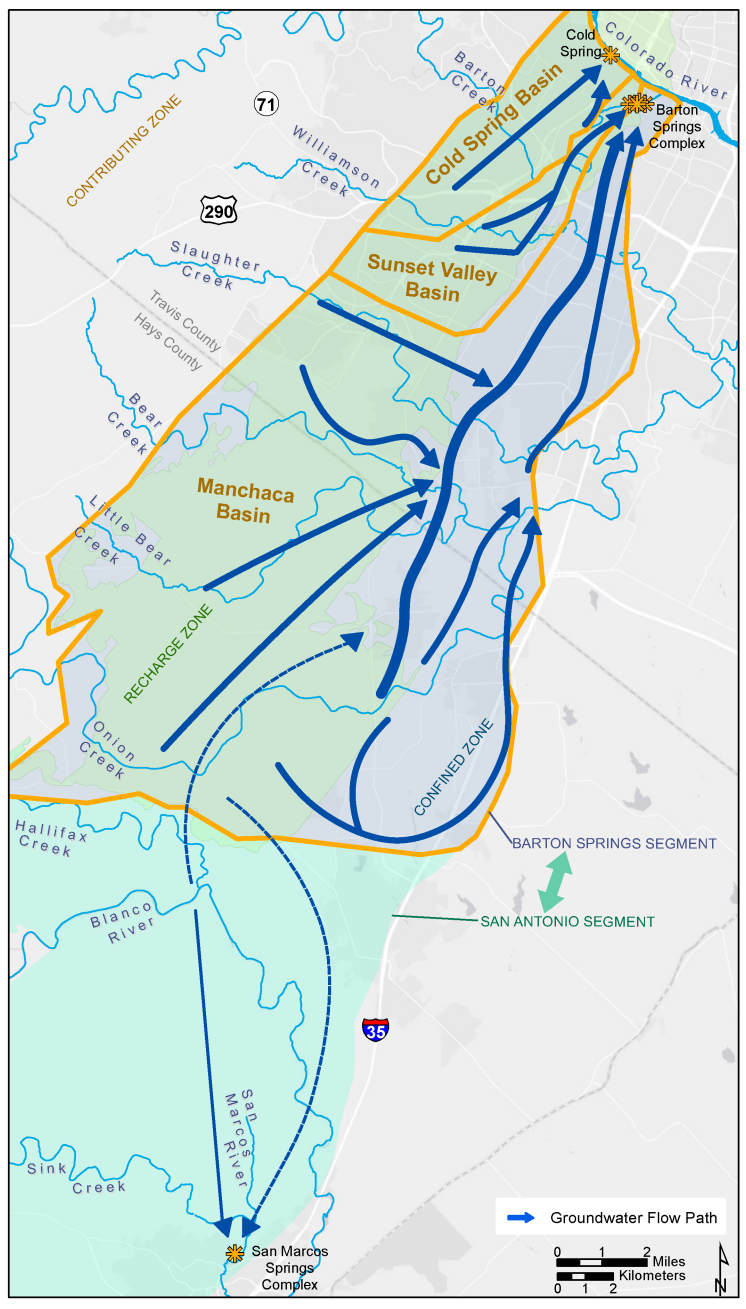

Figure 4. Groundwater flow paths and basins as determined by over 20 years of ongoing aquifer tracing studies (from Zappitello and Johns, 2018b).

al., 2012). Water entering the aquifer through features in these creeks either saturates the matrix material in the aquifer or flows through the conduit system to discharge at the Barton Springs Complex or Cold Spring.

The Barton Springs complex consists of four major springs discharging from the Edwards Aquifer: Main Barton Spring, Eliza Spring, Old Mill Spring, and Upper Spring. Main Barton Spring discharges into the pool; Eliza Spring is north of the pool and surrounded by a historical amphitheater which the public can view but not enter; Old Mill Spring is downstream and east of the pool and also surrounded by a historical amphitheater kept private from the public; and Upper Spring discharges into Barton Creek upstream of the pool. The springs complex is habitat for two federally endangered salamanders: the Barton Springs Salamander (Eurycea sosorum) and the Austin Blind Salamander (Eurycea waterlooensis). The springs are important for regional water resources and contribute up to $20 \%$ of the downstream discharge in the Colorado River, the largest surface water body in Austin. The municipal swimming pool is a popular and economically important recreation center, attracting nearly one million paid visitors in 2018 (fees are only collected during high season). Because of the important services it provides and its inherent sensitivity to potential contamination, the springs complex has been well-studied for several decades.

\section{Decades of Data}

WPD, in collaboration with regulatory partners, has established and maintained a groundwater tracing program since 1996 (Hauwert et al., 2004; Hunt et al., 2005; Smith et al., 2006; Hauwert, 2009; Smith et al., 2012; Hauwert, 2012; Hunt et al., 2013; Zappitello and Johns, 2018a). The tracing program has provided detailed flow path and groundwater velocity data. This information has allowed the BSEA to be further subdivided into three groundwater basins that flow to different springs in the Barton Springs complex and Cold Spring (Figure 4). Groundwater in the Cold Spring Basin flows to Cold Spring on the south bank of the Colorado River, approximately 3 kilometers northwest of the Barton Springs Complex. Groundwater in the Sunset Valley Basin discharges from Upper Spring and, to a lesser extent, from Old Mill Spring. Groundwater in the Manchaca Basin discharges from Main Barton, Eliza, and Old Mill Springs, with Old Mill Spring also receiving some influence from the saline zone. Groundwater velocities vary depending on aquifer conditions and drought cycles, but tracer arrival times usually range from hours to days depending on the injection site, sometimes weeks during drought.

In addition to the tracing work that has been done, the City of Austin has collected physicochemical parameters on a 15-minute interval since 1993. The United States Geological Survey (USGS) has collected this data continuously on behalf of the City since 2007 and makes it available in near real-time (hourly uploads) on their website. Parameters collected include specific conductance, dissolved oxygen, turbidity, temperature, $\mathrm{pH}$, and discharge (determined by a rating curve corresponding to the level in a nearby well). This data has proven invaluable in revealing how the springs, and thus the aqui- 
fer, behave under different conditions including drought, rapid recharge following rain events, and even lowering the water level in the pool for cleaning.

Armed with this knowledge about aquifer function and response, WPD maintains a catastrophic spill response plan for incidents in the Barton Springs Zone.

\section{Barton Springs Spill Response Plan}

The City of Austin has robust programs in place for the investigation and mitigation of pollution discharges to waterways throughout the city, with staff performing approximately 1,250 investigations each year. The oldest is the Spill Response Program, which began in 1987 and was expanded in 1990 to meet the requirements of Phase I of the National Pollutant Discharge Elimination System (40 CFR 122, 124). This program investigates all discharges of pollution throughout the City's jurisdiction, seeking compliance and mitigation for any illegal activities.

A specific plan for spill response in the Barton Springs Zone was developed in 2003. At the time, the entire known habitat of the endangered salamanders was limited to the four springs within the Barton Springs Complex. As a result, the City was required to obtain and maintain a 10(a)(1)(B) incidental take permit with the US Fish and Wildlife Service (PRT-839031). Measure No. 36 of the permit states "The City will, in concurrence with the Service, develop a catastrophic spill response plan for Barton Springs...This plan will address spill prevention, containment, remediation, and salamander rescue." The plan specifically lays out roles and procedures for dealing with various events which could threaten the habitat and population of salamanders within Barton Springs Pool. Since initial implementation, the plan has gone through multiple revisions and updates to incorporate aquifer information gained from groundwater tracing and other research. Recommended courses of action vary depending on pollutant type, spill volume, and discharge at Barton Springs, which is an indicator of groundwater velocity and thus contaminant transport time.

\section{Forensic Investigation}

Given that the alert received by WPD was a photo of Plume 2 sent to the Salamander Team Lead's smartphone, the initial response involved mobilizing to Barton Springs with available sample bottles, a multiparameter water quality sonde, and a chlorine analyzer. Due to the unknown nature and source of the plume, the pool was closed to the public and all swimmers were asked to leave, after which point the first priority was to ensure the safety of the endangered salamanders, or to begin a rescue if they were in danger. Chlorine was not detected, and all other field parameters aside from turbidity were within typically observed ranges. WPD staff examined salamanders and their behavior at the more easily accessed habitat in Eliza Spring (where white sediment was also discharging) and observed salamanders swimming, seemingly unaffected by their cloudy environment, indicating that an immediate rescue would not be necessary.

\section{Initial Response and Gathering Evidence}

Once swimmers had been evacuated from the pool and the immediate health of the salamanders had been verified, WPD staff visited the other springs in the complex to determine which ones were impacted by the white sediment. As already stated, Eliza Spring was discharging white sediment like Main Spring, in visually similar concentrations (Zappitello et al., 2019). Old Mill Spring appeared minimally affected, and Upper Spring was completely unaffected, thus ruling out the Cold Spring and Sunset Valley Basins as potential source areas for the sediment. The (visually) lower turbidity at Old Mill Spring indicated the source of the sediment was closer to the Main Spring conduit flow path than the areas on the eastern edge of the confined zone near the saline zone.

With the potential search area somewhat narrowed based on this information, WPD Water Quality Compliance specialists first contacted Austin Water to determine if there were any active water main breaks in the area. They then worked with the City's Development Services Department (DSD) to obtain information on all active construction sites within the area of interest, since the white color of Plume 2 resembled either construction site runoff or well grout at first glance. However, no rain had fallen in the days preceding Plumes 1 and 2, so construction runoff without an associated leak or misuse of water on-site was not a leading theory. DSD agreed to send out inspectors to assist the WPD staff in investigating these sites. WPD Water Quality Compliance staff also checked the creeks in the recharge zone for evidence of high turbidity flow entering the aquifer and canvassed nearby neighborhoods for signs of drilling or construction activity.

Shortly after all four springs in the complex had been checked for sediment, water discharging from Main 
Barton Spring began to clear, although the sediment suspended in the pool continued to circulate for several hours. WPD hydrogeologists used this time to examine the past 24 hours of data collected by the USGS sonde and develop a more directed search plan to find the source of the plume. This information was used to create a map assigning search areas to WPD and DSD staff for the following day.

\section{Turbidity Concentrations in Barton Springs}

Turbidity in Barton Springs Pool typically hovers around 1.4 Formazin Nephelometric Units (FNU) under baseflow conditions. Plume 2 turbidity peaked at 28.4 FNU when WPD staff were present, but during review of the recorded turbidity data it became apparent that Plume 1 the previous evening had been even more concentrated, with turbidity peaking at 79 FNU (Figure 5). Lifeguards on duty the evening of December 18th had taken photos of Plume 1 and provided them to WPD staff when they were on site responding to Plume 2 the following day. The first and larger plume had been brown in color rather than the white sediment from Plume 2 that was still circulating in the pool. WPD staff were also present on December 20th when Plume 3 discharged into the pool, peaking at 11.2 FNU while the search for the sediment source was still underway. Plume 3 was brown in color, similar to Plume 1, suggesting that these discharges were discrete releases of different materials and not natural phenomena.

Turbidity increases at Barton Springs are typically the result of storm events, but there had been no recent rainfall in the days preceding the sediment plumes, and the sediment plume responses did not mimic the physicochemical responses observed following storms. During storms when the aquifer is rapidly recharged by runoff, (1) the specific conductance at the springs drops as a result of fresher water diluting the mineralized water that has been in storage, and (2) the turbidity rises as a result of the increased sediment loads carried by storm runoff entering the aquifer. Turbidity measured in the pool during these events rarely rises above 10 FNU except when Barton Creek floods the pool to such an extent that the cave where the multiparameter probe is housed becomes inundated with flood water (a rare occurrence).

No change in specific conductance was observed during any of the three plume discharges. A heavy rainfall event several days after Plume 3 (Figure 5) illustrates a typical spring response to rapid recharge of storm runoff; specific conductance dropped due to the influx of freshwater, and turbidity rose due to sediment-laden runoff entering the aquifer through recharge features. The recovery for both specific conductance and turbidity following the storm took days, with turbidity returning to baseline levels more quickly than specific conductance.

During storms like the one that occurred a few days after the sediment discharges, the highly turbid creek water entering the aquifer through karst features carries increased concentrations of nonpoint source pollutants. In order to enhance the quality of water entering the aquifer, BSEACD maintains an automated intake structure for the largest capacity recharge cave in the area, Antioch Cave on Onion Creek (Smith and Hunt, 2017). To limit pollutant loads into this feature, the structure's valves close automatically when turbidity in Onion Creek exceeds 100 Nephelometric Turbidity Units (NTU), then reopen when the turbidity drops back below 50 NTU. Measurements at Antioch Cave to enable the valves' operation also provide a record of turbidity in Onion Creek, which contributes the highest fraction of recharge to the aquifer of the six creeks crossing the recharge zone (Slade et al., 1986). Turbidity is reported in both FNU and NTU in this paper because, although the units NTU and FNU are functionally equal, they are measured using different instrumentation.

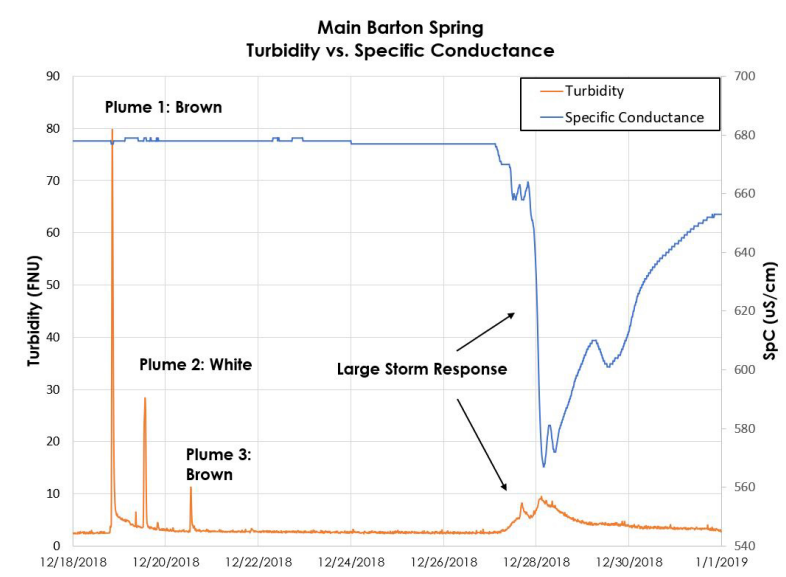

Figure 5. Turbidity and Specific Conductance Responses in Barton Springs. Turbidity responses to the three sediment plumes in contrast with a typical turbidity and specific conductance response to a large storm event (rainfall totals of 5-9.5 cm or 2-3.75 inches) several days later. 
As shown for two recent storm events in Figure 6, the turbidity concentration response at Main Barton Spring under high flow conditions is on the order of $0.5-1 \%$ of the turbidity in Onion Creek during flooding, assuming these are representative responses. The slightly higher turbidity spike early on May 4, 2019 is a result of the most significant flood at Barton Springs Pool in 90 years and includes a brief period of measuring Barton Creek floodwaters entering the pool with enough force to circulate against spring flow into the cave where the multiparameter probe is housed. If this period is excluded, none of the spring turbidity responses to these storms at Main Barton exceed the values measured during the December 2018 sediment plumes. Further note that the turbidity recovery following these storm events occurs over days rather than over hours as observed following the sediment plumes.

\section{Limited Dispersion from Source to Spring}

Discharge at the springs was approximately $2.83 \mathrm{~m}^{3} / \mathrm{s}$ $\left(100 \mathrm{ft}^{3} / \mathrm{s}\right)$ during the event, which is above average. Under high aquifer conditions, groundwater velocities up to $495 \mathrm{~m} / \mathrm{hr}$ (7.4 mi/day) have been documented by tracing (Smith et al., 2006), indicating a release at a site several kilometers away could still arrive at the springs within a day. However, a nearer source seemed likely to WPD hydrogeologists based on the swift arrival and abrupt dissipation of the plumes.

Minimal dispersion indicated that the source was most likely nearby and anthropogenic based on previous ob-

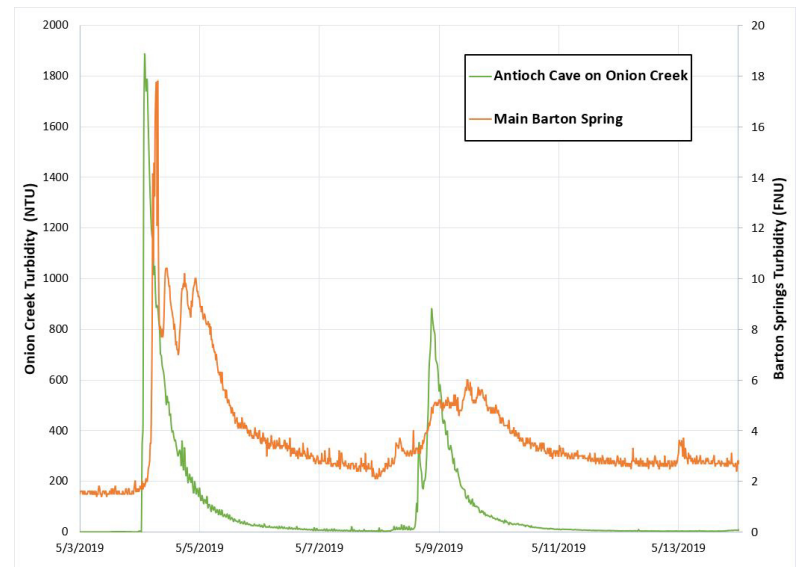

Figure 6. Storm Turbidity Responses in Onion Creek and Main Barton Spring. Turbidity Responses in Main Barton Spring vs. flooding Onion Creek at Antioch Cave, approximately $25 \mathrm{~km}$ (15.5 miles) south of Barton Springs. Note 100x difference in scale. servations of natural turbidity responses. This is evident in the relatively gradual arrival and departure of the turbidity response to the storms in Figures 5 and 6 above. Even when material is introduced rapidly, such as dye injected during groundwater tracing, dye injected at sites farther from the springs or away from conduit flow paths disperses and takes longer to flush through the system. Figure 7 shows how dye injected into a feature $23.7 \mathrm{~km}$ (14.75 mi) from Barton Springs took hours to peak once detected and then days to return to baseline concentrations.

\section{Plume Arrival Times}

Assuming that these sediment discharges were generated nearby and during typical working hours (assumed to be anywhere from approximately 7:00 to $18: 00$ ), the likely source area could be further narrowed. Plume 1 arrived at approximately 20:15, indicating that the source of the release was likely at least 2 hours away assuming no work was done after 18:00 or so. Similarly, Plumes 2 and 3 arrived at 12:45 and 13:00, respectively, indicating that the source of the discharge was likely no more than 6 hours away, assuming based on the limited dispersion of the sediment within the aquifer that the releases had occurred on the same day they arrived at the springs. Spatially, this made it most likely that the source was $0.5 \mathrm{~km}-3 \mathrm{~km}$ from Main Barton Spring.

On December 20, 2018, WPD staff returned to Barton Springs Pool shortly before 12:45, the time that Plume 2

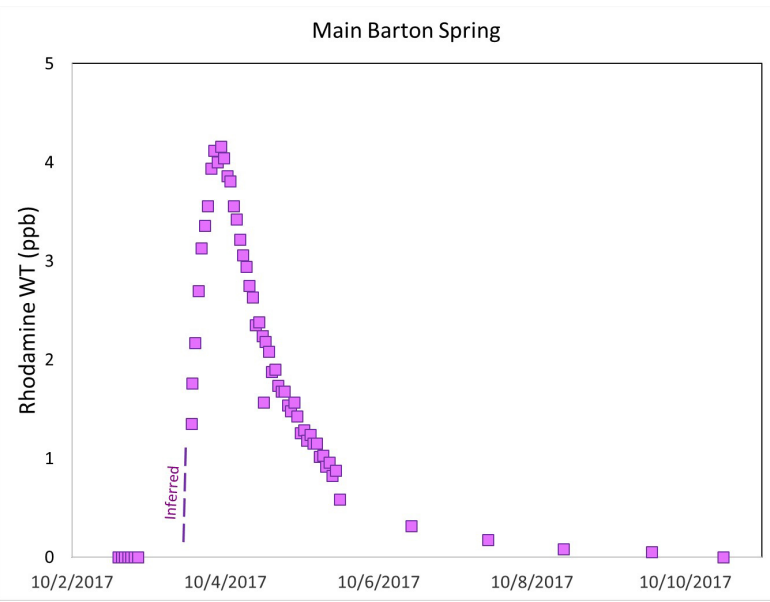

Figure 7. Dye Trace Breakthrough Curve and Recovery. Dye injected into Fenceline Sink on Little Bear Creek (23.7 km/14.75 mi from Main Barton Spring) takes days to return to baseline levels (Zappitello and Johns, 2018a). 
occurred the previous day. When brown sediment began discharging at approximately the same time (Plume 3) as Plume 2 had the previous day, it confirmed the likelihood for investigators that it was related to activity early in the workday causing impacts a few hours later. Plume 3 was shorter in duration and lower in turbidity than the previous two, and once again was brown instead of white, emphasizing for investigators that these were discrete discharges of different materials. WPD staff suspected at the time that the different materials may have been drilling mud when brown and bentonite grout used for well completion when white.

A summary of the principal lines of evidence available to investigators at the time is provided in Table 1.

\section{Source Location and Justification}

Following the release of Plume 3 on December 20th when many WPD responders were still present at the pool, a WPD water quality compliance specialist was canvassing the nearby neighborhood and investigated a small drill rig operating at a residential construction site. The location was approximately 1,250 meters southsouthwest of Main Barton Spring (Figure 8).

Conversations with the driller revealed that, during the previous few days while drilling heat pump wells for a residential geothermal heating and cooling system, the crew had encountered a void on the evening of Decem-

\section{Summary of Available Evidence:}

- The affected springs were Main Barton and Eliza, with minimal suspended sediment visible at Old Mill and none at Upper Barton, thus limiting the source area to the Manchaca Basin

- Plumes were different colors

- No chlorine: ruled out water line leak

- No elevated bacteria levels: ruled out wastewater line leak

- Recharging creeks were flowing clear: ruled out contaminant discharges to waterway and restricted potential source to void encounters or discharges directly into recharge features

- No physical parameters outside of typical ranges other than turbidity

- Turbidity concentrations were greater than during any previously observed natural events and much sharper, indicating discrete releases

- Lack of significant dispersion indicated nearby source and discrete releases

- Episodic nature of plumes and timing with typical working hours narrowed likely travel times

- Approximate range of groundwater velocities known for high discharge conditions based on previous groundwater tracing studies

Table 1. Summary of available evidence. ber 18th shortly before shutting down for the day. On the morning of December 19th, they grouted that same well and had to use more grout than typical for a well of that size because they kept losing material to the void. They had also encountered a smaller void while drilling a different well that morning of December 20th.

The timing of these events was consistent with travel times of 3 to 4 hours. The void on December 18th had been encountered at some time after 17:00, and Plume 1 arrived at 20:15. The driller's notes recorded that grouting on the morning of December 19th began at approximately 9:00, and Plume 2 arrived at Main Barton Spring at 12:45. The smaller void encountered on the morning of December 20th was also breached at some point after 9:00, and Plume 3 arrived at the pool at 13:00. Straight-line travel times from the residence to Main Barton Spring would then have been approximately between 315 and $415 \mathrm{~m} /$ hour. It is likely, based on when the plumes arrived at Eliza Spring following arrival at Main Barton Spring (Eliza Spring is $104 \mathrm{~m}$ from Barton Spring), that the travel time was closer to 3 hours than 4

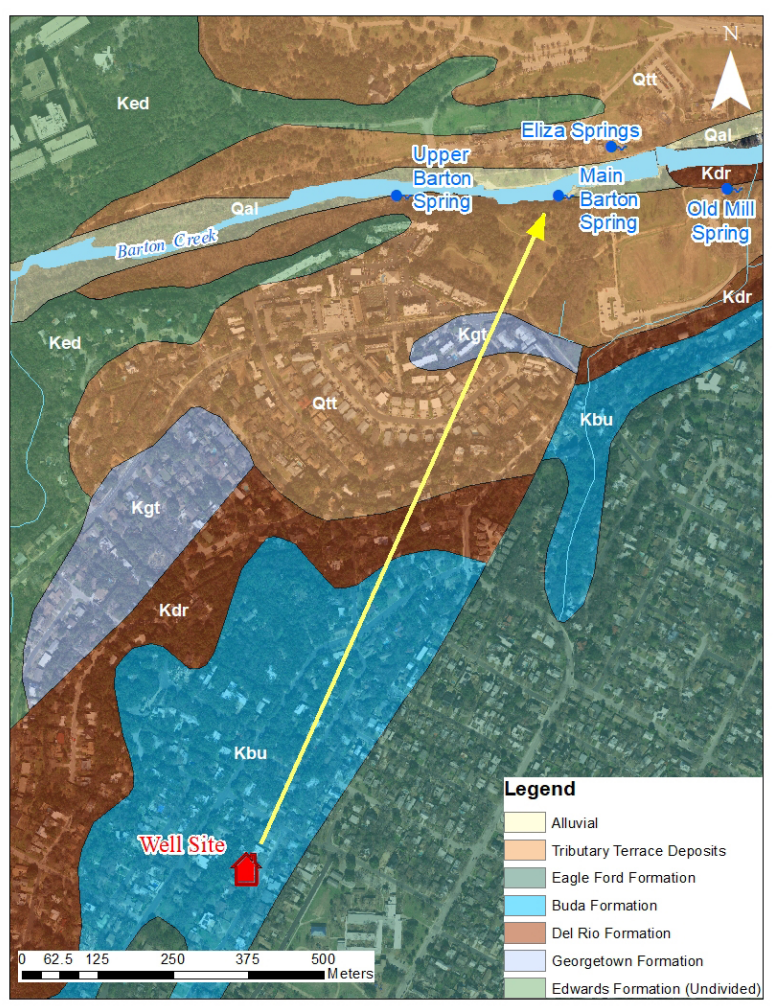

Figure 8. Geologic Map of Flow Path from Well Site to Main Barton Spring. The well site is in the confined zone approximately 1,250 meters upgradient from Main Barton Spring. 
(Zappitello et al., 2019). For example, even though the process of grouting is recorded as having begun at 9:00 on the morning of December 19th, the actual grout may not have been poured down-hole until some point thereafter, once it had been mixed, and more continued to be added as it escaped into the conduit.

Although investigators' original hypothesis for the differences in color between plumes was that drilling mud was responsible for the brown plumes and grout was responsible for the white plume, investigators learned that the driller had been using air rotary to drill the wells. The air rotary method runs air at a high pressure through a hollow-stem drill bit to return cuttings from the bottom of a borehole to the surface. Since no mud was used in this process, the most likely scenario for Plumes 1 and 3 is that when the drill bit broke through into the waterfilled voids, the high air pressure mobilized sediment that had previously been immobile, or possibly opened a previously clogged conduit.

\section{Enforcement Actions}

All officials present at the residential heat pump well system site agreed that the drilling activity there was the likely source of the sediment discharges to Barton Springs. The DSD Enforcement Coordinator issued a Stop Work Order to cease all construction activities and a misdemeanor citation for Discharge of Pollution to a Waterway on December 20, 2018. The Stop Work Order was provisionally lifted on December 21, 2018 to allow the driller and builder to complete the drilling project under close supervision by BSEACD staff.

Continuation of the project was also contingent on a redesign of the system. The system had been designed for ten wells $76 \mathrm{~m}$ ( 250 feet) deep. Based on the driller's notes and target depths for the geothermal system's wells, the total depth of the wells and the void horizon encountered were both below the elevation of Main Barton Spring (128 meters or 419 feet above mean sea level $(\mathrm{msl})$ ), which is only approximately $66 \mathrm{~m}$ (217 feet) below the elevation of the project site (194 meters or 636 feet msl). The target total depth of the wells easily put them within the zone to intercept conduits within the aquifer (Figure 9). To limit this risk, drilling was allowed to resume with BSEACD supervision under the condition that wells were drilled only to a total depth at least ten feet above the previously encountered void horizon, which meant that more wells had to be installed at the shallower depth to achieve the same level of heat exchange for the geothermal system.

\section{Conclusions \& Implications}

The Edwards Aquifer tracing program is critical to understanding the sensitive Barton Springs system and has given us the knowledge to effectively manage the risks associated with it being a publicly accessible endangered species habitat surrounded by rapid urbanization. Information obtained from these studies over the past 23 years was key to finding the source of these plumes in just over 24 hours after receiving the initial notification. Furthermore, although this was not a planned tracing event, the sediment plumes acted as groundwater tracers and revealed the location of what is likely a major conduit on the primary flow path to Barton Springs.

Continuous collection of 15-minute field parameters at the spring with access to hourly internet data uploads proved invaluable in the investigation and response to this event. Without this data there would have been no information other than the lifeguards' photographs for the first plume, and the full duration of the second plume would not have been captured. The physicochemical data allowed scientific characterization of the arrival, peak, and duration of the sediment discharge to within +/- 15 minutes.

As a result of this event, the BSEACD worked with WPD staff to revise guidelines for well drilling in the BSEA. The revised guidelines apply to all wells permitted by BSEACD in a prioritized management zone that geologists from both organizations agreed was most

Geologic Cross Section from Well Site to Barton Springs

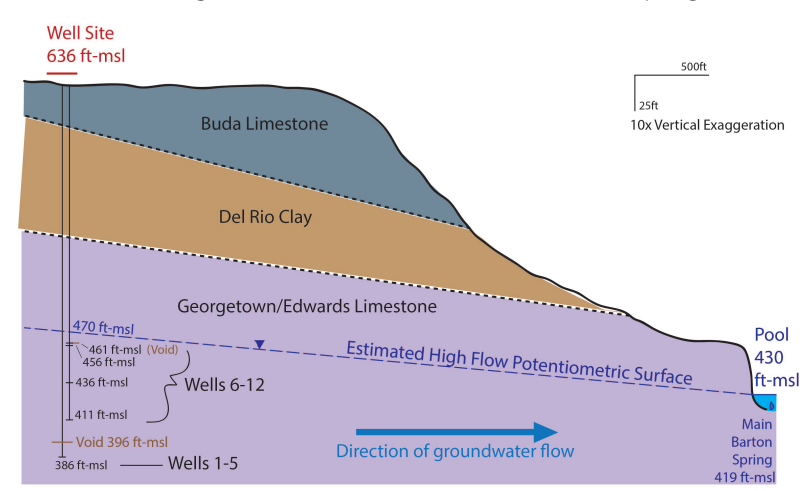

Figure 9. Geologic Cross Section from 1912 Paramount Drive to Main Barton Spring. Cross section depicting drilled well depths at the site intercepting the water table. 
sensitive to impacts that could affect the springs. These guidelines include limiting non-production wells such as the heat pump wells involved in this incident to total depths above the known water table, prohibiting the use of drilling techniques that could introduce contaminants (mud rotary, foam, acidization), and requiring more conservative grouting and well-completion techniques when grout loss is encountered.

Finally, the communication protocols between agencies and departments have been improved as a result of this event. The permitting process within city limits is parsed out to different agencies depending on the project. The project that led to these releases held a drilling permit from BSEACD but was not required to seek a drilling permit from the City of Austin (municipalities do not regulate groundwater in the State of Texas), which made it challenging for city officials to locate the site. BSEACD now notifies WPD of all drilling activity within the management zone 48 hours prior to breaking ground. Additionally, staff at the pool have been given instructions on the appropriate avenue for alerting WPD to any abnormal activity observed at the pool. The photo they sent to the Salamander Team Lead effectively triggered the Barton Springs Spill Response Plan, but it was nearly 16 hours after the first sediment plume on the evening of December 18th. The notification was enough in this case due to the nontoxic nature of the sediment released, but it may not have been sufficient in different circumstances. Pool staff now follow a protocol requiring them to call WPD's 24-hour spills hotline (although they are welcome to send photos directly to WPD staff as well).

Although this event was not planned, it provided new information similar to a groundwater tracing study and a unique opportunity for testing and improvement of the catastrophic spill response plan. No humans or animals were harmed during these plume discharges, and regular monitoring of the springs and the salamander population have shown no lasting impacts to the aquifer or its unique and endangered inhabitants.

\section{Acknowledgements}

Special thanks to Brian Hunt and Justin Camp with the BSEACD for providing turbidity data from Antioch Cave and everyone in the City's Watershed Protection and Development Services Departments who was involved in the response to this event and the ensuing enforcement actions.

\section{References}

Bradshaw K. 2018 December 19. Photograph appearing in "Barton Springs Pool to remain closed until Friday, Austin officials say" Austin AmericanStatesman; [updated 2018 December 20; cited 2019 September 18]. Available from: https://www. statesman.com/news/20181219/bartob-springspool-to-remain-closed-until-friday-austin-officialssay.

Brune G. 2002. Springs of Texas. 2nd ed. College Station (TX): Texas A\&M University Press. p. 430 .

Hauwert N, Johns D, Aley T, Sansom J. 2004. Groundwater Tracing Study of the Barton Springs Segment of the Edwards Aquifer, Southern Travis and Northern Hays Counties, Texas: Report by the Barton Springs/Edwards Aquifer Conservation District and City of Austin Watershed Protection and Development Review Department. 110 p. and appendices.

Hauwert N. 2009. Groundwater Flow and Recharge Within the Barton Springs Segment of the Edwards Aquifer, Southern Travis and Northern Hays Counties, Texas. PhD Dissertation, University of Texas at Austin. 316 p.

Hauwert N. 2012. Dye Trace Simulation of an Accidental Spill, Phase 10: State Highway 45 Southwest and MoPac South into the Barton Springs Segment of the Edwards Aquifer, Travis County, Texas. City of Austin, Watershed Protection Department, Short Report SR-13-01.

Hunt B, Smith B, Campbell S, Beery J, Hauwert N, Johns D. 2005. Dye tracing recharge features under high-flow conditions, Onion Creek, Barton Springs Segment of the Edwards Aquifer, Hays County, Texas. Austin Geologic Society Bulletin, Vol. 1, p. 70-86.

Hunt B, Smith B, Adams M, Hiers S, Brown N. 2013. Cover-Collapse Sinkhole Development in the Cretaceous Edwards Limestone, Central Texas. Proceedings of the 13th Multidisciplinary Sinkhole Conference on Sinkholes and Engineering and Environmental Impacts of Karst, Carlsbad New Mexico, May 2013, p. 89-102.

Johnson S, Schindel G, Veni G, Hauwert N, Hunt B, Smith B, Gary M. 2012. Tracing Groundwater 
Flowpaths in the Vicinity of San Marcos Springs, Texas. Edwards Aquifer Authority Report No. 12-01.

Slade R Jr, Dorsey M, Stewart S. 1986. Hydrology and water quality of the Edwards Aquifer associated with Barton Springs in the Austin area, Texas. USGS Water-Resources Investigations Report 86-4036.

Smith B, Hunt B, Beery J. 2006. Summary of 2005 Groundwater Dye Tracing, Barton Springs Segment of the Edwards Aquifer, Hays and Travis Counties, Central Texas. BSEACD Report of Investigations 05012006. $31 \mathrm{p}$.

Smith B, Hunt B, Johnson S. 2012. Revisiting the Hydrologic Divide Between the San Antonio and Barton Springs Segments of the Edwards Aquifer: Insights from Recent Studies: Gulf Coast Association of Geological Societies Journal, Vol. 1, p. 55-68.

Smith B, Hunt B. 2017. Recharge and Water-Quality Controls for a Karst Aquifer in Central Texas In: White WB et al., editors. Advances in Karst Science. Proceedings of the Karst Groundwater Contamination and Public Health Conference; 2017 Jan; San Juan, Puerto Rico: p. 299-317.

Zappitello SJ, Johns DA. 2018a. 2017 Groundwater Tracing in the Barton Springs Edwards Aquifer: Onion Creek and Little Bear Creek. City of Austin Watershed Protection Department Short Report SR-18-10. 29 p.

Zappitello SJ, Johns DA. 2018b. A Robust Color Palate: The Latest Chapter in 20+ Years (and Counting) of Barton Springs Edwards Aquifer Tracing. Oral Presentation. Geological Society of America Annual Meeting; 2018 Nov. 4-7; Indianapolis, IN, United States.

Zappitello SJ, Johns DA, Sydow L. 2019 (in review) Hydrogeologic Connectivity of two Major Spring Orifices: Main Barton and Eliza Springs Texas. Paper in progress for Proceedings of the Conference on Sinkholes and the Engineering and Environmental Impacts of Karst; 2020 Apr. 20-24; San Juan, Puerto Rico. 